\title{
Implications of changes in amplitude and contour of the mercury strain gauge plethysmograph pulse tracing
}

\author{
P. A. N. CHANDRARATNA, S. SAN PEDRO, R. SCHNEIDER, \\ D. ABRAMS, AND J. LANGEVIN \\ From the Division of Cardiology, the University of Oklahoma Health Sciences Center, \\ Oklahoma City, Oklahoma, U.S.A.
}

SUMMARY Alterations in the mercury strain gauge plethysmograph pulse tracing have been previously thought to denote changes in venous tone. This study was designed to define the implications of changes in amplitude and contour of pulse tracing. Seven normal subjects were studied. After control measurements, amyl nitrite was administered and the pulse tracing was recorded. When the haemodynamic state had returned to control levels $0.4 \mathrm{mg}$ sublingual glyceryl trinitrate (GTN) was given. The amplitude of the plethysmograph pulse tracing $(\mathrm{Y} \mathrm{mm})$ and the vertical distance from the dicrotic notch to the peak of the pulse tracing (X mm) were measured. With amyl nitrite, the amplitude of the pulse tracing $(\mathrm{Y})$ decreased from $10.4 \pm 1$ to $4.5 \pm 0.6 \mathrm{~mm}$ (mean \pm SEM), while the $\mathrm{X} / \mathrm{Y}$ ratio increased from $0.7 \pm$ 0.02 to $0.98 \pm 0.02(\bar{P}<0.005)$. After GTN $Y$ increased from $9.3 \pm 0.8$ to $31 \pm 4.8 \mathrm{~mm}(P<0.005)$ and $\mathrm{X} / \mathrm{Y}$ ratio increased from $0.7 \pm 0.06$ to $0.99 \pm 0.01(\mathrm{P}<0.005)$. Since it is known that amyl nitrite produces venoconstriction and arteriolar dilatation, and GTN causes venous and arteriolar dilatation, we conclude that an increase in $\mathrm{Y}$ reflects venous dilatation, and an increase in $\mathrm{X} / \mathrm{Y}$ ratio, that is a fall in the dicrotic notch, denotes arteriolar dilatation. Thus, the plethysmograph pulse tracing can be used to assess the effects of drugs on the capacitance and resistance beds.

Several investigators have shown the value of the mercury strain gauge plethysmograph in assessing the blood flow to a limb (Whitney, 1953; Strandness et al., 1961; Holling et al., 1961). Experimental studies have shown that the amplitude of the plethysmograph pulse tracing is influenced by venous tone (Parrish et al., 1963). An increase in amplitude of the pulse tracing denotes venodilatation and a decrease in amplitude implies venoconstruction. Little attention has been paid to the implications of changes in the position of the dicrotic notch of the plethysmograph pulse. The purpose of this paper is to show that the amplitude of the plethysmograph pulse is determined by venous tone and the position of the dicrotic notch is mainly influenced by arteriolar tone.

\section{Subjects and methods}

The group studied consisted of 7 normal subjects

Received for publication 10 August 1977 whose ages ranged from 24 to 34 years. There were 3 men and 4 women. The subjects were in the recumbent position during the study, which was carried out in a room at a constant temperature of $24 \cdot 4^{\circ} \mathrm{C}\left(76^{\circ} \mathrm{F}\right)$. All studies were done in the basal postabsorptive state. The legs were covered by a blanket. A mercury loop was attached to the second toe of the right foot and connected to a Parks model 270 plethysmograph. The sensitivity was kept constant throughout the procedure. Blood pressure was measured with a sphygmomanometer. Five baseline blood pressure and heart rate recordings were made. The mercury strain gauge plethysmograph pulse was recorded continuously until its amplitude stabilised. Amyl nitrite was inhaled for 10 seconds from a broken ampoule held over the nose. The plethysmograph pulse was recorded continously. The pulse and blood pressure were recorded at 15-second intervals. Ten minutes after the haemodynamic state had stabilised, and the plethysmograph pulse amplitude was stable, $0.4 \mathrm{mg}$ glyceryl trinitrate was given sublingually and the above measurements repeated. 
Table

\begin{tabular}{|c|c|c|c|c|c|c|c|c|c|c|c|c|}
\hline Case No. & $A g$ & and sex & $B P c_{1}$ & $B P A N$ & $H R c_{1}$ & $H R A N$ & $C_{1} A M P$ & $A N A M P$ & $C_{1} X / Y$ & $A N X / Y$ & $B P c_{2}$ & $B P G T$ 畜 \\
\hline $\begin{array}{l}1 \\
2 \\
3 \\
4 \\
5 \\
6 \\
7 \\
\text { MEAN } \\
\text { SEM } \\
\text { P }\end{array}$ & $\begin{array}{l}31 \\
34 \\
30 \\
27 \\
29 \\
27 \\
24\end{array}$ & $\begin{array}{l}F \\
F \\
F \\
M \\
M \\
F \\
M\end{array}$ & $\begin{array}{c}180 / 60 \\
130 / 80 \\
134 / 78 \\
126 / 92 \\
94 / 54 \\
104 / 80 \\
112 / 66 \\
115 / 73 \\
6 / 5\end{array}$ & $\begin{array}{c}60 / 20 \\
98 / 70 \\
110 / 70 \\
94 / 58 \\
74 / 50 \\
78 / 48 \\
92 / 30 \\
87 / 50 \\
7 / 8 \\
<0.005\end{array}$ & $\begin{array}{r}76 \\
80 \\
80 \\
74 \\
80 \\
76 \\
76 \\
77 \\
1\end{array}$ & $\begin{array}{c}120 \\
115 \\
128 \\
120 \\
124 \\
132 \\
120 \\
123 \\
2 \\
<0.005\end{array}$ & $\begin{array}{c}7 \\
11 \\
10 \\
8 \\
11 \\
11 \\
15 \\
10 \cdot 4 \\
1\end{array}$ & $\begin{array}{l}3.5 \\
5 \\
4 \\
4 \\
6 \\
2 \\
7 \\
4.5 \\
0.64 \\
<0.005\end{array}$ & $\begin{array}{l}0.6 \\
0.64 \\
0.7 \\
0.7 \\
0.8 \\
0.7 \\
0.75 \\
0.7 \\
0.02\end{array}$ & $\begin{array}{l}0.9 \\
1 \\
1 \\
1 \\
1 \\
1 \\
1 \\
0.98 \\
0.02 \\
<0.005\end{array}$ & $\begin{array}{r}108 / 72 \\
124 / 80 \\
140 / 78 \\
126 / 92 \\
98 / 58 \\
108 / 76 \\
114 / 66 \\
117 / 75 \\
14 / 11\end{array}$ & $\begin{array}{r}102 / 60 \bar{\varrho} \\
118 / 800 \\
124 / 78 \overline{\bar{O}} \\
114 / 92 \\
88 / 600 \\
98 / 78 \\
104 / 680 \\
107 / 74 \\
12 / 12 \\
\star<0.005\end{array}$ \\
\hline
\end{tabular}

$\mathrm{BPc}_{1} \quad=$ Control blood pressure $(\mathrm{mmHg})$ before the inhalation of amyl nitrite

BPAN $=$ Blood pressure after amyl nitrite

$\mathrm{HR}_{\mathrm{C}_{1}} \quad=$ Control heart rate (beats/minute) before amyl nitrite

HRAN = Heart rate after amyl nitrite

$\mathrm{C}_{1} \mathrm{AMP}=$ Control amplitude $(\mathrm{mm})$ of the mercury strain gauge pulse, before amyl nitrite

ANAMP = Amplitude of strain gauge pulse $(\mathrm{mm})$ after amyl nitrite

$\mathrm{C}_{1} \mathrm{X} / \mathrm{Y}=$ Control $\mathrm{X} / \mathrm{Y}$ (see Fig. 2)

$\mathrm{AN} \mathrm{X} / \mathrm{Y}=\mathrm{X} / \mathrm{Y}$ ratio after amyl nitrite

$\mathrm{BPc}_{2}=$ Control $\mathrm{BP}$ before glyceryl trinitrate

BPGTN = BP after glyceryl trinitrate

$\mathrm{HRC}_{2}=$ Control HR before glyceryl trinitrate

HRGTN = Heart rate after glyceryl trinitrate.

$\mathrm{C}_{2} \mathrm{AMP}=$ Control amplitude of the strain gauge pulse before glyceryl trinitrate

GTNAMP = Amplitude of the strain gauge pulse after glyceryl trinitrate

$\mathrm{C}_{2} \mathrm{X} / \mathrm{Y}=$ Control $\mathrm{X} / \mathrm{Y}$ ratio before glyceryl trinitrate

GTN X/Y $=X / Y$ ratio after glyceryl trinitrate

SEM = Standard error of mean

The asterisk denotes that the $P$ value applies only to the systolic blood pressure.

\section{Results}

The results of the study are outlined in the Table. The heart rate increased after amyl nitrite inhalation. A less striking increase in heart rate was

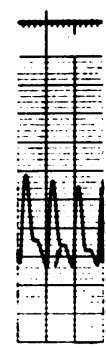

Control

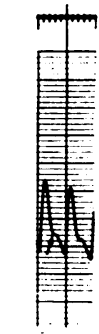

Control

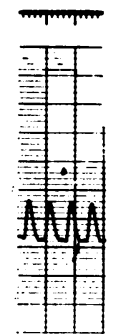

Amyl nitrite

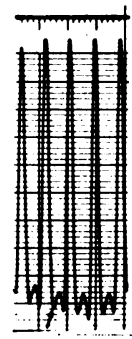

GTN
Fig. 1 Mercury strain gauge plethysmograph pulse tracings of case 7. On the top left panel is the control record before amyl nitrite inhalation. The arrow indicates the position of the dicrotic notch. Note that when amyl nitrite is given (top right), the amplitude of the pulse decreases and the dicrotic notch (arrow) falls to the baseline. The bottom left panel shows the control tracing before the administration of glyceryl trinitrate. After glyceryl trinitrate (bottom right panel) there is a striking increase in the amplitude of the pulse and a fall of the dicrotic notch (arrow) to the baseline. observed after glyceryl trinitrate. There was a fall in the systolic blood pressure ranging from $48 \mathrm{mmHg}$ to $20 \mathrm{mmHg}$ during amyl nitrite inhalation. A slight fall in systolic blood pressure was observed after the administration of glyceryl trinitrate.

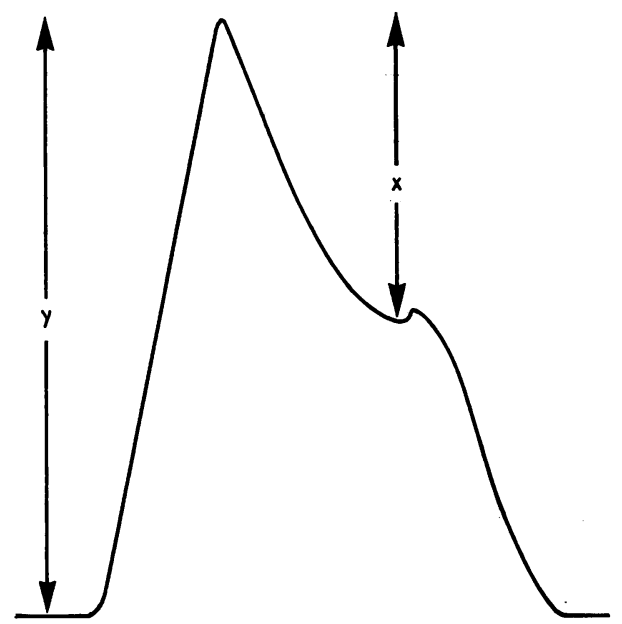

Fig. 2 A diagrammatic sketch of the strain gauge pulse is shown. The vertical distance from the dicrotic notch to the peak of the pulse is $X$. The amplitude of the pulse is $Y$. The ratio $X / Y$ denotes the relative position of the dicrotic notch. $A$ rise in the $X / Y$ ratio denotes a fall in the dicrotic notch. 
e

\begin{tabular}{cclll}
\hline HRGTN & $C_{2}$ AMP & \multicolumn{2}{l}{ GTN AMP $C_{2} X / Y$} & $G T N X / Y$ \\
\hline 84 & 6 & 15 & 0.5 & 0.9 \\
88 & 10 & 25 & 0.7 & 1 \\
100 & 9 & 20 & 0.7 & 1 \\
92 & 7 & 30 & 0.7 & 1 \\
86 & 10 & 34 & 0.8 & 1 \\
92 & 11 & 44 & 0.7 & 1 \\
80 & 12 & 48 & 0.8 & 1 \\
89 & 9.3 & 31 & 0.7 & 0.99 \\
3 & 0.8 & 4.8 & 0.06 & 0.01 \\
$<0.005$ & & $<0.005$ & & $<0.005$ \\
\hline
\end{tabular}

The contour of the normal mercury strain gauge plethysmograph pulse tracing and the changes that occurred after administration of drugs are illustrated in Fig. 1. The normal plethysmograph pulse tracing has an ascending limb and a descending limb with a dicrotic notch (Fig. 2). The amplitude $(Y)$ of the tracing, and the vertical distance $(X)$ from the dicrotic notch to the peak of the pulse were measured. The ratio $\mathrm{X} / \mathrm{Y}$, therefore,

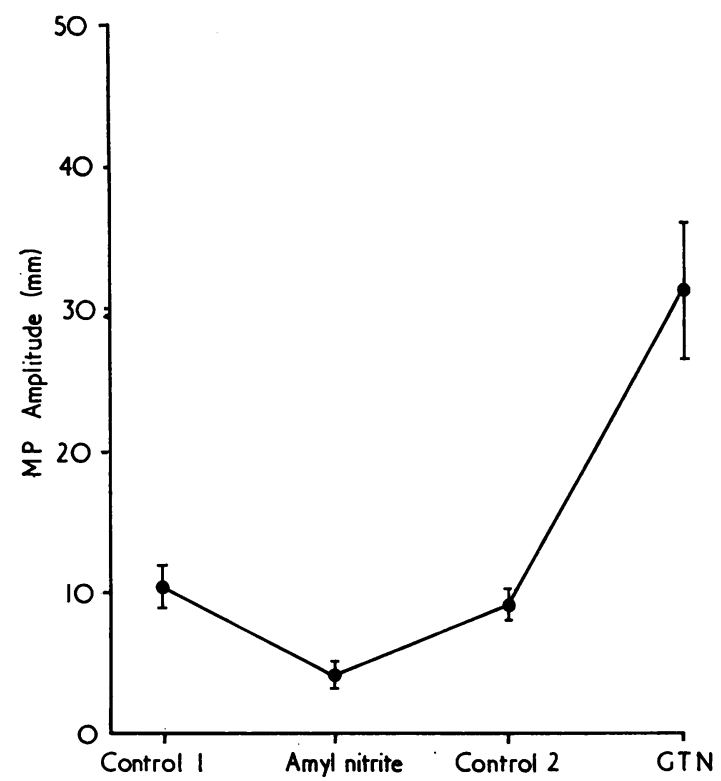

Fig. 3 The amplitude of the mercury strain gauge plethysmograph pulse tracing (MP) is shown on the vertical axis. The mean and the standard error of the mean are shown. Note that there is a decrease in amplitude with amyl nitrite inhalation. In contrast glyceryl trinitrate causes a distinct increase in pulse amplitude.

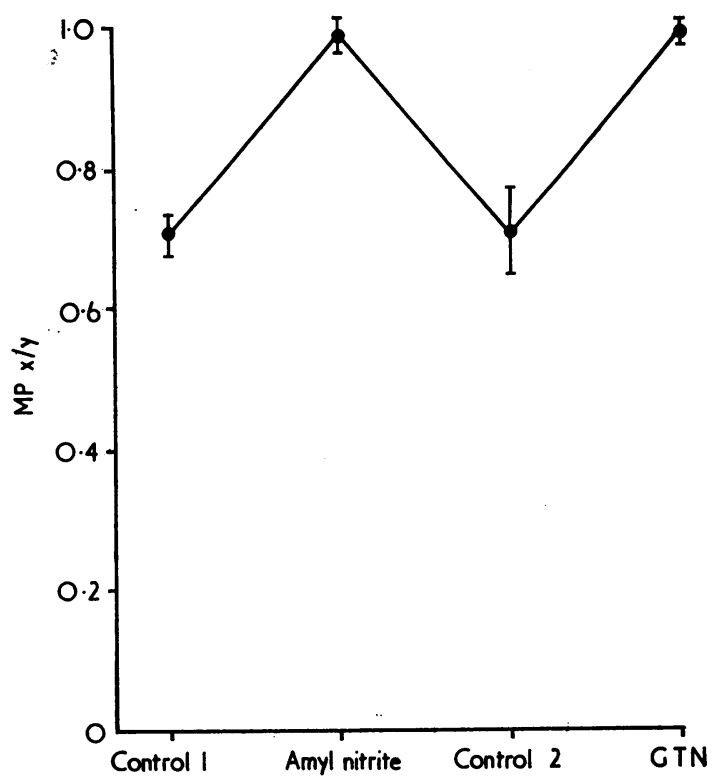

Fig. 4 The ratio $X / Y$ of the mercury strain gauge pulse $(M P)$ is shown on the vertical axis. Note that both amyl nitrite and glyceryl trinitrate cause an increase in the $X / Y$ ratio.

indicated the relative position of the dicrotic notch on the descending limb. For instance a fall in the dicrotic notch would be indicated by an increase in the $X / Y$ ratio. After inhalation of amyl nitrite the amplitude of plethysmograph pulse tracing decreased, whereas the $X / Y$ ratio increased. After the administration of glyceryl trinitrate an increase in amplitude of the plethysmograph pulse tracing and an increase in $X / Y$ ratio were observed. The individual values for the pulse tracing are given in the Table, and the mean values for the group together with the standard error of the mean are depicted in Fig. 3 and 4. The amplitude of the pulse tracing decreased from a mean of $10.4 \mathrm{~mm}$ to a mean of $4.5 \mathrm{~mm}$ after amyl nitrite; whereas the amplitude increased from a mean of $9.3 \mathrm{~mm}$ to a mean of $31 \mathrm{~mm}$ after glyceryl trinitrate. The dicrotic notch fell to or near the baseline after each intervention as reflected by an increase in the $\mathrm{X} / \mathrm{Y}$ ratio.

\section{Discussion}

Our studies indicate that glyceryl trinitrate causes a distinct increase in amplitude of the plethysmograph pulse tracing, together with a fall in the dicrotic notch to or near the baseline. In contrast, amyl nitrite resulted in a reduction of the amplitude of the plethysmograph pulse tracing with a concomitant fall in the dicrotic notch to or near the base- 
line. Mason and Braunwald have shown that glyceryl trinitrate causes venodilatation as well as arteriolodilatation, whereas amyl nitrite causes venoconstriction and arteriolodilatation (Mason and Braunwald, 1965). Therefore we deduce that an increase in amplitude of the plethysmograph pulse tracing indicates venodilatation, and conversely a decrease in amplitude of the plethysmograph pulse denotes venoconstriction. Since both glyceryl trinitrate and amyl nitrite produce arteriolodilatation a fall in the dicrotic notch towards the baseline is evidence of dilatation of the resistance vessels. Our results are consonant with those of Parrish and associates who noted a distinct similarity between the plethysmographic readings and changes that occurred in small vein pressure (Parrish et al., 1963). They concluded that changes in the mercury strain gauge plethysmograph pulse tracing primarily reflected changes in venous volume. However, these workers failed to recognise that a fall in the dicrotic notch towards the baseline implies arteriolodilatation. It should be pointed out that amyl nitrite causes a distinct increase in the cardiac output (Perloff et al., 1963). In spite of this effect, the amplitude of the plethysmograph tracing decreased, indicating that the amplitude of the plethysmograph pulse is a more sensitive index of venomotor tone than total blood flow to a given area.

It should be emphasised that a careful maintenance of a constant room temperature is of utmost importance in obtaining reliable results. A progressive rise of the ambient temperature may cause venodilatation and result in misinterpretation of data. In our studies the room temperature was maintained constant by means of an air conditioner.

In summary, the influence of amyl nitrite and glyceryl trinitrate on the amplitude and dicrotic notch of the mercury strain gauge plethysmograph pulse was studied. Our results indicate that the amplitude of the plethysmograph pulse is influenced by venous tone, whereas a fall in the dicrotic notch reflects arteriolodilatation. Thus the plethysmograph pulse tracing may be used to study the effects of drugs on the venous and arteriolar beds.

\section{References}

Holling, H. E., Boland, H. C., and Russ, E. (1961). Investigation of arterial obstruction using a mercury-in-rubber strain gauge. American Heart fournal, 62, 194-205.

Mason, D. T., and Braunwald, E. (1965). The effects of nitroglycerin and amyl nitrite on arteriolar and venous tone in the human forearm. Circulation, 32, 755-766.

Parrish, D., Bray, R. A., Strandness, D. E., Jr., and Bell, J. W. (1963). Evidence for the venous origin of plethysmographic information. Fournal of Laboratory and Clinical Medicine, 62, 943-949.

Perloff, J. K., Calvin, J., De Leon, A. C., and Bowen, P. (1963). Systemic hemodynamic effects of amyl nitrite in normal man. American Heart fournal, 66, 460-469.

Strandness, D. E., Radke, H. M., and Bell, J. W. (1961). Use of a new simplified plethysmograph in the clinical evaluation of patients with arteriosclerosis obliterans. Surgery, Gynecology and Obstetrics, 112, 751-756.

Whitney, R. J. (1953). The measurement of volume changes in human limbs. Fournal of Physiology, 121, 1-27.

Requests for reprints to Dr P. A. N. Chandraratna, Division of Cardiology, Veterans Administration Hospital, Long Beach, California 90822, USA. 